\title{
Participação Política: uma revisão dos modelos de classificação
}

Recebido:

12.09.11

Aprovado:

10.04.12
Julian Borba ${ }^{1}$

Resumo: Considerando o intenso debate teórico e metodológico existente na Sociologia Política sobre participação, nosso objetivo será realizar um mapeamento da literatura internacional sobre as diferentes propostas de tipologias classificatórias das modalidades de participação política. $\mathrm{O}$ artigo destaca que os desdobramentos de tal debate são de fundamental importância para o aperfeiçoamento da capacidade analítica da disciplina em perceber as transformações no universo da participação. Finaliza com um conjunto de proposições em termos de caminhos metodológicos para o avanço nas pesquisas da área.

Palavras-chave: Participação Política, Cultura Política, Política Comparada.

\section{Introdução}

enômenos, como o declínio generalizado nos índices de comparecimento eleitoral e de ativismo partidário, a emergência e expansão dos movimentos de protesto e de novas formas de ação política não diretamente ligadas ao momento eleitoral, têm levado a uma crescente preocupação dos cientistas políticos com o tema da participação.

Os esforços vão desde a definição conceitual, passando pelos condicionantes do engajamento político, chegando às tipologias classificatórias. Considerando a existência de certo consenso nas recentes definições de participação política (TEORELL, TORCAL \& MONTERO, 2007; PASQUINO, 2010; BRADY, 1999) e de alguns esforços recentes no sentido de mapear os determinantes do engajamento (VERBA, SCHOLOZMAN \& BRADY, 1995; NORRIS, 2007; DALTON, 2002; DALTON, SICKLE \& WELDON, 2009; ALDRICH, 1993; LEIGHLEY, 1995; WHITELEY, 1995)², nos deteremos, neste artigo, no mapeamento da literatura internacional sobre as diferentes propostas de tipologias classificatórias das modalidades de participação ${ }^{3}$.

Trata-se de uma área onde se tem verificado um intenso e rico debate teórico e metodológico, cujos desdobramentos são de fundamental importância, seja na capacidade analítica da disciplina em perceber as transformações no universo da participação, verificadas no tempo e no
1. Universidade Federal de Santa Catarina, Centro de Filosofia e Ciências Humanas, Departamento de Sociologia e Ciência Política.

E-mail: julian@cfh. ufsc.br

2. Os trabalhos listados acima, em geral, abordam os determinantes do engajamento no nível individual. Para um estudo que toma os países como unidade de análise, ver Newton e Girebler (2008).

3. Por razões de espaço, não trataremos, no presente artigo, do imenso debate que tem ocorrido no Brasil sobre o tema da participação política. Em outros trabalhos, tivemos a oportunidade de analisar tal literatura. Ver, em especial, Ribeiro e Borba (2010a), Ribeiro e Borba (2010b), Borba (2011a), Borba (2011b). 
espaço (VAN DETH, 2001), seja na possibilidade de construção de instrumentos que sejam capazes de mensurar tais transformações (BRADY, 1999; TEORELL, TORCAL \& MONTERO, 2007). Afinal de contas, como nos alerta Henry Brady, a tarefa de classificar e nomear os fenômenos do mundo social está diretamente relacionada com a forma como atribuímos sentido a ele. Nas suas palavras:

(...) Nomear, distinguir e contar frequentemente são consideradas tarefas científicas prosaicas - cabíveis para curadores de museu, amadores refinados, bibliotecários e estatísticos do governo, mas não para cientistas de primeira linha. Essa perspectiva modificou-se conforme filósofos da ciência, linguistas, psicólogos cognitivos e cientistas praticantes mostraram como as nossas conceitualizações, taxonomias e classificações subjazem às nossas visões de mundo. O modo como nomeamos e classificamos as coisas tem muito a ver com o modo como as compreendemos. Para os cientistas sociais, essa visão é duplamente importante, porque devemos nos preocupar com as categorias naturais - com o modo como as pessoas comuns nomeiam e classificam as coisas e compreendem o mundo - além de com o modo como nosso empreendimento científico nomeia e classifica as coisas. (BRADY, 1999, p. 740)

O artigo está organizado em três partes, além desta. Na primeira, abordamos brevemente alguns conceitos de participação política. Na segunda, nos detemos num balanço das principais tipologias de classificação, para, então, nas considerações finais, propor alguns caminhos metodológicos para o avanço nas pesquisas sobre participação política.

\section{O Conceito de Participação}

Desde o seminal trabalho de Milbrath (1965), tem-se assistido a uma profusão de conceitos de participação. Tais definições, como bem destacou Van Deth (2001), estão diretamente articuladas ao contexto em que os próprios atos de participação operam. Se, nos anos de 1960, a definição se estruturava, sobretudo, em função das modalidades eleitorais, os novos repertórios que começam a fazer parte da ação coletiva, desde então, (protestos, boicotes, etc.) obrigam que sejam, de alguma maneira, incorporados pelas definições de participação.

A tradição de pesquisas que inicia com Milbrath (1965), de início, definia a participação como o conjunto de atividades relacionadas ao momento eleitoral. Sugestivas dessa interpretação são as definições de Verba e Nie, para os quais, 
por participação política deve-se entender “(...) atividades realizadas por cidadãos privados que buscam, de modo mais ou menos direto, influenciar a seleção dos funcionários governamentais e/ou as ações que eles tomam" (p. 2). De maneira similar, para Huntington e Nelson (1976), trata-se de uma atividade "realizada por cidadãos privados com o objetivo de influenciar a tomada de decisão do governo" (p. 17).

Tal definição é por demais restritiva, seja ao definir a influência como o único repertório "político", bem como ao colocar o "governo" como destinatário, por excelência, do ato político (PASQUINO, 2010; TEORELL, TORCALL \& MONTERO, 2007). Ora, a literatura de movimentos sociais tem exemplos variados para mostrar que, desde os anos 1960, assiste-se a uma ampliação significativa naquilo que poderíamos chamar de repertórios políticos, para além da simples tentativa de influenciar as decisões governamentais; além do mais, como mesmo chegam a reconhecer Verba e colaboradores, nem toda ação política está direcionada ao governo, podendo ser destinada a destinada a "alocações de valores para uma sociedade" (VERBA \& NIE, 1972, p. 2)

Assim, parecem mais apropriadas definições como as de Boot e Seligson (1976, p. 6), que a conceituam como "um comportamento que influencia ou tenta influenciar a distribuição dos bens públicos". Mais recentemente, considerando também as mudanças no âmbito da participação política, Brady a definiu como "a ação de cidadãos comuns com o objetivo de influenciar alguns resultados políticos" (1999, p. 737, grifos no original) ${ }^{5}$. Veja-se que os dois conceitos acima elencados já não definem um destinatário dos atos participativos (se governo ou não). Mesmo assim, pode-se perceber alguns limites em tal definição, ao delimitar a "influência" como único objetivo da participação, excluindo, por exemplo, a ação direta exercida por determinados grupos. (TEORELL, TORCALL \& MONTERO, 2007, p. 336) ${ }^{6}$. Para nossos propósitos, porém, ela é suficiente para podermos avançar em nosso mapeamento da literatura.

\section{As Modalidades de Participação}

Os conceitos de participação apresentados acima se materializam em diferentes indicadores empíricos, os quais, por sua vez, se transformam em medidas de participação passíveis de ser verificadas empiricamente ${ }^{7}$. Tais medidas se materializam em modalidades de participação, das quais, com a posse dos dados empíricos, temos a possibilidade de verificar sua frequência, evolução, comparar países, identificar determinantes, etc.

A leitura dos trabalhos (e a discussão que apresentaremos abaixo) procurou sistematizar três dimensões do debate. Em primeiro lugar, o método e as técnicas
4. Um dos exemplos de ação política listados por vários autores, como Teorell, Torcal e Montero (2007) e Van Deth (2007), que não é direcionado aos governantes, é o boicote de certos produtos.

5. Pasquino oferece definição semeIhante, de alguma maneira incluindo a ação direta. Em suas palavras: "A participação política é o conjunto de acções e de comportamentos que aspiram a influenciar, de forma mais ou menos direta e mais ou menos legal, as decisões dos detentores do poder no sistema político ou em organizações políticas particulares, bem como a própria escolha daqueles, com o propósito de manter ou modificar a estrutura (e, consequentemente, os valores) do sistema de interesses dominante" (2010, p. 74), grifos no original.

6. Nesse sentido, um aspecto importante a ser destacado com essas definições é que todas elas estão situadas no âmbito das institucionalidade do modelo democrático representativo e, portanto, são congruentes com determinadas concepções da teoria democrática (em especial, aqui, a versão do elitismo competitivo). 
Outras definições de democracia implicam que outros conceitos e práticas sejam incorporados ao conceito de participação (cf. TEORELL, 2006).

7. Não é por demais lembrar que a literatura de que estamos tratando aqui é fundamentalmente tributária dos desenvolvimentos metodológicos experimentados pela Ciência Política, a partir dos anos 1940 e 1950, em especial com o desenvolvimento das técnicas de amostragem e das pesquisas de opinião pública, as quais possibilitaram a guinada comportamentalista no âmbito da disciplina, cujos trabalhos precursores podem ser encontrados em Lazersfeld et al. (1948), Berelson (1952), Campbell (1960) e Almond e Verba (1989).

8. Brady (1999) faz sua resenha a partir das pesquisas que deram origem aos trabalhos mencionados.

9. A base empírica de tais trabalhos é - American National Election Survey, uma pesquisa nacional, aplicada desde 1952. de pesquisa utilizados na análise; em segundo lugar, os componentes da tipologia proposta e, por fim, o diagnóstico quanto à dimensão uni ou multidimensional dos atos participativos. Quanto a este último aspecto, significa diferenciar os atos participativos entre um continuum (visão unidemensional), onde os indivíduos exerceriam as diferentes modalidades em função de habilidades ou custos para a participação, ou percebê-los como constituídos por diferentes modalidades que possuem padrões de recrutamento, bases atitudinais e sociodemográficas distintas em termos dos seus participantes (BRADY, 1999).

Devemos salientar, também, que nosso trabalho foi facilitado pela existência de um balanço de literatura já realizado por Brady (1999), o qual procedeu a uma ampla resenha sobre algumas das principais pesquisas, que resultaram nas grandes obras sobre o tema (MILBRATH, 1965; VERBA \& NIE, 1972; VERBA, NIE \& KIM, 1978; BARNES \& KASE, 1979; VERBA, SCHLOZMAN \& BRADY, 1995) ${ }^{8}$. Dessa forma, nos limitaremos a apresentar de maneira muito breve tais trabalhos (a - os estudos clássicos), para nos concentrar nos desenvolvimentos observados a partir da década de 1990 (b - novas tipologias).

\section{a) Os Estudos Clássicos}

Como já comentado acima, talvez o primeiro esforço de elaboração de uma tipologia das modalidades de participação possa ser encontrado em Milbrath $(1965)^{9}$. Para esse autor, os comportamentos participativos ocorreriam no seguinte continuum, em termos de custos e complexidade:

1) expor-se a solicitações políticas;

2) votar;

3) participar de uma discussão política;

4) tentar convencer alguém a votar de determinado modo;

5) usar um distintivo político;

6) fazer contato com funcionários públicos;

7) contribuir com dinheiro a um partido ou candidato;

8) assistir a um comício ou assembleia;

9) dedicar-se a uma campanha política;

10) ser membro ativo de um partido político;

11) participar de reuniões onde se tomam decisões políticas;

12) solicitar contribuições em dinheiro para causas políticas;

13) candidatar-se a um cargo eletivo;

14) ocupar cargos públicos.

Veja-se que a ideia de um continuum de custos e complexidade leva a uma 
percepção da participação política como um fenômeno unidimensional, ou seja, para Milbrath, participar é um ato singular, mesmo que algumas de suas medidas empíricas demonstrassem o baixo nível de relacionamento entre algumas das variáveis, em especial, entre o "voto" com as demais modalidades de participação (BRADY, 1999, p. 745). No seu modelo, os cidadãos são divididos em três grupos, de acordo com o nível de engajamento. Teríamos os passivos (que não participam), os espectadores (envolvimento mínimo) e os "gladiadores" (ativistas). Tais níveis seriam cumulativos e formariam uma pirâmide, onde as atividades mais complexas seriam aquelas desenvolvidas pelos cidadãos mais centrais da estrutura social. Daí a formulação de Milbrath ser denominada de "modelo da centralidade" (MILBRATH, 1965).

Uma segunda abordagem ao estudo da participação foi desenvolvida por Alessandro Pizzorno, uma das mais ambiciosas construções teóricas até hoje identificadas no âmbito de uma teoria da participação. O centro de seu argumento situa-se no questionamento do modelo da centralidade. Como contraponto a esta, defende o modelo da consciência de classe, onde a participação seria produto da identidade política compartilhada pelos atores. Deriva da construção do seu modelo, uma tipologia de participaçao alternativa àquela formulada por Milbrath, a qual, Pizzorno considera reducionista, por estar essencialmente ligada à realidade norte-americana, não conseguindo cobrir a sua expressão em outros contextos. Enfim, trata-se segundo Pizzorno, de conferir um "conteúdo mais geral" (1967, p. 125) às tipologias da participação. Sua proposta de classificação, conforme apresentada abaixo prevê quatro modalidades de seu exercício, as quais são dividas segundo o tipo de solidariedade dominante (se privada ou pública) e pelo contexto da ação (se estatal ou não). A primeira forma de ação "estatal" com "solidariedade política" seria o profissionalismo político ${ }^{10}$. A segunda modalidade seria aquela com ação, também estatal, mas com "solidariedade privada dominante". Nesse caso, teríamos a "participação civil na política"11. Já onde impera a ação extraestatal com solidariedade política, temos a participação através de movimentos sociais ${ }^{12}$. Por fim, tem-se a participação através de "subcultura"13, onde predomina a solidariedade privada com ação extraestatal.

Tabela 1 - Tipologia da Participação Política de Alessandro Pizzorno

\begin{tabular}{|l|l|l|}
\hline & $\begin{array}{l}\text { A solidariedade políti- } \\
\text { ca é prevalente }\end{array}$ & $\begin{array}{l}\text { A solidariedade priva- } \\
\text { da é prevalente }\end{array}$ \\
\hline $\begin{array}{l}\text { Ação inserida no } \\
\text { sistema estatal }\end{array}$ & $\begin{array}{l}\text { Profissionalismo } \\
\text { politico }\end{array}$ & $\begin{array}{l}\text { Participação civil na } \\
\text { política }\end{array}$ \\
\hline Ação extraestatal & Movimento Social & Subcultura \\
\hline
\end{tabular}

Fonte: Pizzorno (1966, p. 125)
10. Nesse caso, a participação define-se pelo fato de o participante "viver da política" ( $p$. $125)$, cujas origens podem ser encontradas numa especialização funcional vivenciada pelas sociedades democráticas ocidentais. A ação do profissional da política deve operar de acordo com a solidariedade política dominante num determinado momento, e não com os interesses da sociedade civil (idem).

11. Seria o tipo de participação que surge a partir da "solidariedade" dos "interesses privados". É exercida pelos círculos mais centrais da estrutura social. Atua em conformidade com os valores da estrutura social existente, cujos indicadores mais típicos seriam a adesão a um "partido de opinião", o pertencimento a associações voluntárias integradas ao sistema, o pertencimento a grupos corporativos, etc. (idem, p. 127).

\footnotetext{
12. A participação no movimento social seria uma "empresa coletiva" destinada a "transformar a sociedade". Tratando-se de uma construção, o movimento, para Pizzorno é um ato de uma identidade construída, onde se relacionam
} 
identidades políticas com identidades privadas. Trata-se de uma forma "não estável de participação", que surge e modifica-se de acordo com o contexto (idem, p. 127).

13. A participação como "subcultura" nasce de uma identificação "natural" do indivíduo com os grupos no qual ele está inserido. Tratase de uma identidade política dada, não construída e, à diferença da participação civil "esta é excluída dos canais normais que se articulam com as instituições estatais, e comunicam-se com essas só através de intermediários (o boss, o organizador do partido de massa que não é mais movimento, etc." (idem, p. 127, tradução minha).

14. O texto original de Pizzorno, "Introduzione allo studio della partecipazione politica" foi publicado originalmente em Quaderni di Sociologia 3/4, pp. 231-287, no ano de 1966. Uma interessante discussão em torno desse trabalho pode ser encontrada na entrevista de Pizzorno (2007).

15. O mais curioso é que o trabalho de Pizzorno passe despercebido pela maioria da literatura que trata do tema da participação política.
Apesar do elevado nível de abstração, da falta de clareza com relação a algumas definições em que sua proposta foi construída, e da dificuldade de sua operacionalização empírica (PASQUINO, 2010), o modelo de Pizzorno teve o grande mérito de antecipar, em pelo mais de dez anos ${ }^{14}$, o debate das modalidades não convencionais de participação (BARNES \& KAASE, 1979), ao colocar a participação em movimentos sociais como uma das modalidades de participação política. Além disso, ao inserir o tema da identidade, o autor também estava antecipando muitos dos achados de Verba, Schlozman e Brady (1995), quando propuseram que a participação política seria função de recursos possuídos pelos indivíduos (em especial, tempo, dinheiro e habilidades). Vejase que a identidade, na forma como definida por Pizzorno, estando relacionada a uma dimensão organizacional da vida associativa, seria, sobretudo uma forma de adquirir habilidades, mesmo diante da falta dos recursos de tempo e dinheiro ${ }^{15}$. Por fim, sua teoria trata a participação como um fenômeno essencialmente multidimensional.

Os primeiros esforços de abordagem empírica comparativa do fenômeno da participção vão ser desenvolvidos em Verba, Nie e Kim (1971), Verba e Nie (1972) e Verba, Nie e Kim $(1978)^{16}$, onde ao invés do continuum do modelo de Milbrath, propõem que a participação política se estruturia através de quatro modalidades (como em Pizzorno) ${ }^{17}$. São elas: voto, atividade de campanha, contato político e atividade cooperativa ${ }^{18}$ (Tabelas 1 e 2, abaixo). Tais dimensões foram extraídas a partir de testes de correlação interna entre as variáveis e de análises fatoriais que permitiram seu agrupamento nas dimensões acima ${ }^{19}$.

Tabela 2 - Variáveis e tipologias de participação em Verba e Nie (1972)

\begin{tabular}{|l|l|}
\hline Variáveis & Modalidades de participação \\
\hline Persuadir outros para votar & Atividades de campanha \\
\hline Trabalhar ativamente para partido ou candidato & Atividades de campanha \\
\hline Participar de reuniões políticas ou comícios & Atividades de campanha \\
\hline Contribuir dinheiro para partido ou candidato & Atividades de campanha \\
\hline $\begin{array}{l}\text { Membro de clubes políticos } \\
\text { Votou nas eleições presidenciais de 1964 }\end{array}$ & Voto \\
\hline Votou nas eleições presidenciais de 1960 & Voto \\
\hline Frequência de votos nas eleições locais & Voto \\
\hline $\begin{array}{l}\text { Trabalhou com outros para resolver problemas } \\
\text { locais }\end{array}$ & $\begin{array}{l}\text { Atividade cooperativa e contato } \\
\text { social }\end{array}$ \\
\hline
\end{tabular}




\begin{tabular}{|l|l|}
\hline $\begin{array}{l}\text { Formou um grupo de trabalho sobre problemas } \\
\text { locais }\end{array}$ & $\begin{array}{l}\text { Atividade cooperativa e contato } \\
\text { social }\end{array}$ \\
\hline $\begin{array}{l}\text { Participou ativamente em organizações comuni- } \\
\text { tárias para resolução de problemas }\end{array}$ & $\begin{array}{l}\text { Atividade cooperativa e contato } \\
\text { social }\end{array}$ \\
\hline $\begin{array}{l}\text { Manteve contato com lideranças locais - refe- } \\
\text { rência social }\end{array}$ & $\begin{array}{l}\text { Atividade cooperativa e contato } \\
\text { social }\end{array}$ \\
\hline $\begin{array}{l}\text { Manteve contato com lideranças nacionais - } \\
\text { referência social }\end{array}$ & $\begin{array}{l}\text { Atividade cooperativa e contato } \\
\text { social }\end{array}$ \\
\hline $\begin{array}{l}\text { Manteve contato com lideranças locais - refe- } \\
\text { rência personalizada }\end{array}$ & Contato personalizado \\
\hline $\begin{array}{l}\text { Manteve contato com lideranças nacionais - } \\
\text { referência personalizada }\end{array}$ & Contato personalizado \\
\hline
\end{tabular}

Fonte: Adaptação de Verba e Nie (1972, p. 72)

Tabela 3 - As dimensões das atividades políticas e modos de atividade

\begin{tabular}{|c|c|c|c|c|c|}
\hline $\begin{array}{c}\text { Modo de } \\
\text { atividade }\end{array}$ & $\begin{array}{c}\text { Tipo de } \\
\text { Influência }\end{array}$ & $\begin{array}{c}\text { Alcance dos } \\
\text { resultados }\end{array}$ & Conflito & $\begin{array}{c}\text { Iniciativa } \\
\text { requerida }\end{array}$ & $\begin{array}{c}\text { Cooperação } \\
\text { com outros }\end{array}$ \\
\hline Voto & $\begin{array}{c}\text { Alta pres- } \\
\text { são/baixa } \\
\text { informação }\end{array}$ & Coletivos & Conflitual & Pequena & Pequena \\
\hline $\begin{array}{c}\text { Atividade de } \\
\text { campanha }\end{array}$ & $\begin{array}{c}\text { Alta pres- } \\
\text { são/ baixa } \\
\text { a alta infor- } \\
\text { mação }\end{array}$ & Coletivos & Conflitual & Alguma & $\begin{array}{c}\text { Alguma ou } \\
\text { muita }\end{array}$ \\
\hline $\begin{array}{c}\text { Atividade } \\
\text { comunitária }\end{array}$ & $\begin{array}{c}\text { Baixa a alta } \\
\text { pressão/ } \\
\text { alta infor- } \\
\text { mação }\end{array}$ & Coletivos & $\begin{array}{c}\text { Talvez sim/ } \\
\text { Talvez não }\end{array}$ & $\begin{array}{c}\text { Alguma ou } \\
\text { muita }\end{array}$ & $\begin{array}{c}\text { Algum ou } \\
\text { muito }\end{array}$ \\
\hline $\begin{array}{c}\text { Contato } \\
\text { personali- } \\
\text { zado }\end{array}$ & $\begin{array}{c}\text { Alta pres- } \\
\text { são/Alta } \\
\text { informação }\end{array}$ & Particular & $\begin{array}{c}\text { Não confli- } \\
\text { tual }\end{array}$ & Muita & Pequena \\
\hline
\end{tabular}

Fonte: Verba, Nie e Kin (1978, p. 55)

O grande mérito das referidas pesquisas foi, além do aspecto comparativo, sua busca por uma análise desagregada dos atos de participação. Com essa abordagem, puderam chegar a conclusões muito distintas daquelas de Milbrath, de que a participação operaria num continuum. Para esses autores, ao invés de um continuum, teríamos múltiplos níveis, onde os participantes incluídos em cada um deles, teriam atributos sociodemográficos e atitudinais distintos ${ }^{20}$.
16. O próprio Milbrath, em estudo posterior (MILBRA$T H$ \& GOEL, 1977), acaba incorporando a ideia de um modelo multidimensional.

17. As dimensões propostas por Verba e colaboradores estão relacionadas a alguns elementos diferenciadores dos atos participativos. São eles: o tipo de influência exercida sobre os líderes (em termos de pressão e informação); o alcance dos resultados (toda a sociedade ou apenas o indivíduo); o grau de conflito; a quantidade de iniciativa que requer $\mathrm{e}$ a quantidade de cooperação que a iniciativa requer (essa última dimensão foi incluída no estudo de 1978).

18. O estudo incluía, em suas questões, além de perguntas relativas à participação eleitoral e contato com governantes, o envolvimento em grupos (politicos e não políticos) e atividades cooperativas no nível local.

19. Os estudos de 1971 e 1978 abrangeram sete países, sendo eles Áustria, Índia, Japão, Holanda, Estados Unidos e loguslávia.

20. A abordagem proposta por Verba e colaboradores foi testada em outros contextos, 
como é o caso do trabalho de Kalaycioglu e Turan (1981), ao confirmarem empiricamente a validade da classificação das modalidades de participação proposta por Verba, Nie e Kim (1978), num estudo que abrangeu a Turquia, Coreia do Sul e Kênia.

21. Deve-se lembrar também que, no contexto dos anos 1970, a expansão da participação foi tratada como um dos sinais da crise de governabilidade das democracias (CROZIER et al., 1975).

22. Inclui também dados de Itália, Suíça e Finlândia.
O problemático nas classificações propostas nos trabalhos de Verba e colaboradores é o seu reducionismo. Como bem destaca Norris (2007), o modelo analítico por eles desenhado previa apenas o engajamento político do tipo citizenoriented. Tal abordagem, se de alguma maneira conseguia captar os repertórios de participação política mais tradicionais, até os anos 1960, se mostrou reducionista ao não computar o protesto e outras atividades políticas como modalidades de participação. Nas palavras de Norris:

As atividades orientadas para o cidadão, exemplificadas pela participação através do voto e pela filiação a partidos, obviamente continua sendo importante para a democracia, mas hoje representam uma conceitualização estreita demais do ativismo, que exclui algumas das metas mais comuns do engajamento cívico, que se tornaram convencionais e predominantes. (2007, p. 639)

O reconhecimento das modalidades de protesto político nos estudos de participação somente vai receber um tratamento empírico sistemático, em Political action, de Barnes e Kaase (1979). O ponto de partida desse trabalho é o reconhecimento das "ondas de protesto político que varreram as democracias industriais avançadas no final da década de 1970" (BARNES \& KASE, 1979, p. 13, grifos no original). A importância desse reconhecimento está relacionada ao fato de que, até então, o fenômeno da participação massiva e da mobilização política na forma de protestos era associado ao contexto de instabilidade política dos países em desenvolvimento. A maior expressão desse diagnóstico está binômio participação/institucionalização, de Samuel Huntington (1975), bem como nos seus trabalhos específicos sobre participação política em tais contextos (HUNTINGTON \& NELSON, 1976) ${ }^{21}$.

Ao reconhecer as atividades de protesto e contestação como uma modalidade de participação política, percebendo-as não como uma anomalia típica dos países subdesenvolvidos, mas como fenômenos que estavam acontecendo naqueles contextos centrais, em termos de desenvolvimento político e econômico - e sem necessariamente apontar para uma crise de legitimidade das democracias, como chegou a ser apontado em alguns estudos -, tal projeto levou a uma reformulação das próprias formas de mensurar e classificar a participação política, como veremos abaixo.

O projeto Political Action teve início em 1971, reunindo cientistas sociais em torno de um estudo que abrangeu a realidade de cinco países (Áustria, Inglaterra, Holanda, Estados Unidos e Alemanha Ocidental ${ }^{22}$ ). A obra, de 1979, apresenta os resultados de tal pesquisa. Para os nossos propósitos, interessa destacar a tipologia de participação política que é elaborada em tal estudo - e que passa a ser incorporada ao vocabulário dos estudos de participação, desde então -, 
que é aquela divisão entre as "modalidades convencionais" e "não convencionais". No rol das modalidades convencionais, teríamos aquelas já apresentadas acima, constantes dos modelos de Verba e Nie (1972) ${ }^{23}$. Já, como atividades não convencionais, teríamos as relacionadas aos atos de protesto, as quais, numa escala de complexidade (e custos), são: assinar um abaixo-assinado, participar de manifestações legais, participar de boicotes, recusar-se a pagar aluguel ou impostos, ocupar edifícios ou fábricas, bloquear o tráfego com demonstrações de rua, participar de greves ${ }^{24}$.

A tipologia proposta em Political Action percebe a relação entre participação convencional e não convencional não como excludentes, mas como "repertórios"25 mobilizados pelos ativistas, dependendo do contexto. A participação aqui, volta a ser vista como um fenômeno unidimensional, cujas modalidades fazem parte de repertórios, que são mobilizados pelos indivíduos num continuum que envolve custos e complexidade crescentes ${ }^{26}$. Tal continuum foi sistematizado pelos autores numa escala, a "tipologia do repertório de ação política", a qual classifica os indivíduos, entre inativos ${ }^{27}$, conformistas $^{28}$, reformistas ${ }^{29}$, ativistas $^{30}$ e protesters ${ }^{31}$. A escala está apresentada no quadro abaixo:

Tabela 4 - Tipologia do repertório da ação política

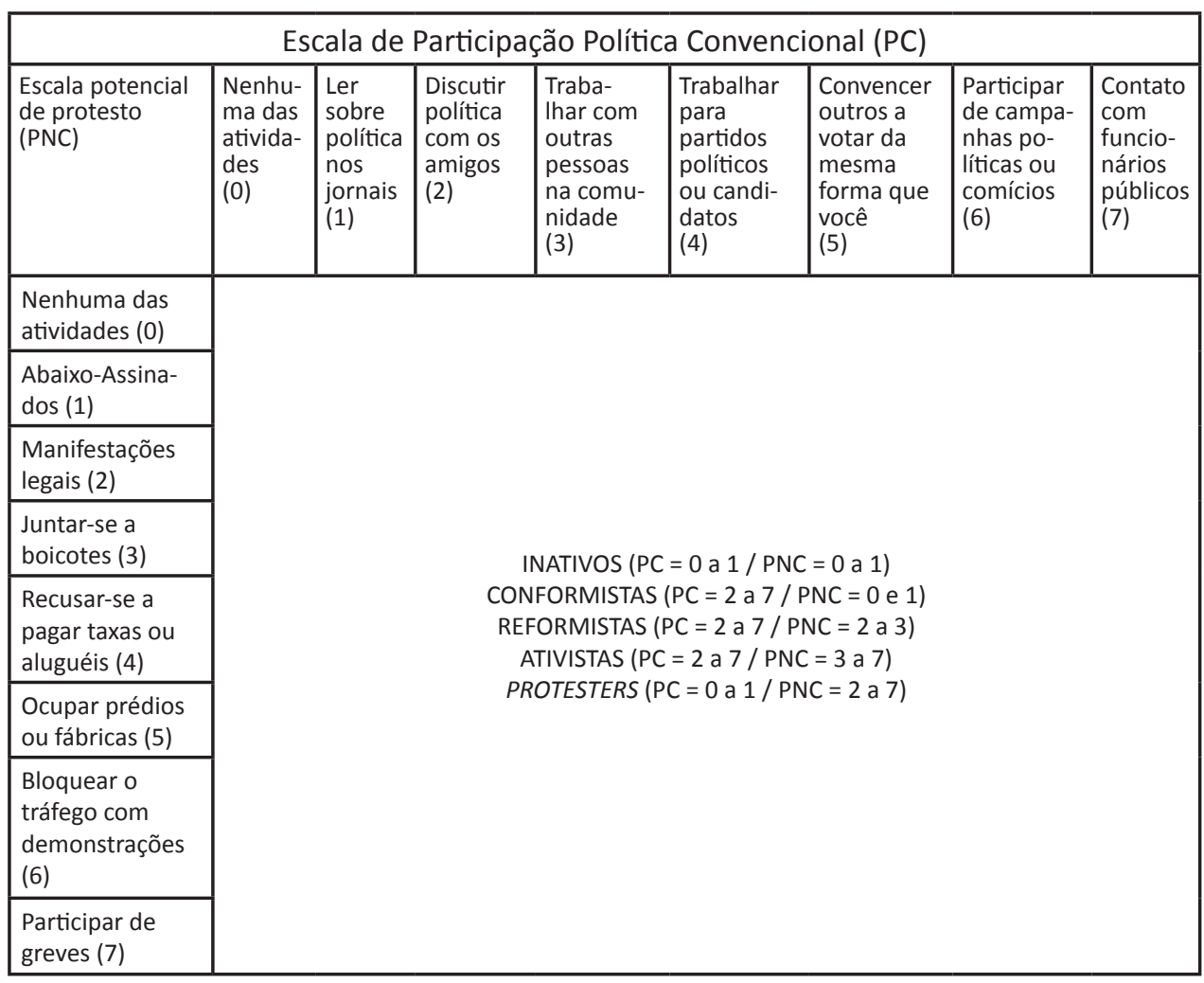

Fonte: adaptado de Barnes e Kaase (1979, p. 154)
23. Além das modalidades já mencionadas em Verba e Nie (1972), os autores incluem "ler sobre política nos jornais" e "discutir política com os amigos", o que leva a um questionamento de Brady (1999), se tais ações realmente poderiam ser enquadradas como modalidades de participação política.

24. Reconhecendose a dificuldade de mensurar atividades episódicas e irregulares, como as de protesto, os autores desenvolvem uma complexa metodologia, que combina a participação em atividades de protesto com a propensão à participar (BARNES \& KAASE, 1979). Para uma análise detalhada da metodologia de Political Action, Brady (1999).

25. A ideia de "repertórios" da ação coletiva vai ganhar tratamento sistemático na obra de um conjunto de autores situados em torno da teoria do processo políti$c o$, entre os quais, Charles Tilly, Sidney Tarrow e Douglas Macdam. Para uma visão de tal perspectiva aplicada ao estudo dos movimentos sociais, ver Tarrow (2009) e Tilly e Tarrow (2007).

26. A metodologia utilizada para construir a 
escala de participação em Political Action foi a escala de Gutmann. Para maiores detalhes sobre tal metodologia, vide Marsh (1974) e Brady (1999).

27. Em termos de dados empíricos, os inativos seriam em número de $17,9 \%$ na Holanda, 30\% no Reino Unido, 12, 3\% nos EUA, 26,6\% na Alemanha e 34,9 na Áustria.

28. Seriam de $11,1 \%$ na Holanda, 15,4\% no Reino Unido, $17,5 \%$ nos EUA, $13,5 \%$ na Alemanha e 19,2\% na Áustria.

29. Seriam de $19,8 \%$ na Holanda, 21,9\% no Reino Unido, $36,0 \%$ nos EUA, $24,6 \%$ na Alemanha e $20,9 \%$ na Áustria.

30. Seriam de $19,3 \%$ na Holanda, 10,2\% no Reino Unido, $14,4 \%$ nos EUA, $8 \%$ na Alemanha e 5,9 na Áustria.

31. Em número de de $31,9 \%$ na Holanda, $22,4 \%$ no Reino Unido, $19,8 \%$ nos EUA, $27,3 \%$ na Alemanha e $19,1 \%$ na Áustria.

32. A distinção entre participação "convencional" e "não convencional" tem sido recorrentemente utilizada nos principais trabalhos que se ocupam do comportamento político, em que pesem algumas adaptações conceituais, veja-se
Como amplamente reconhecido pela literatura, Political Action foi um divisor de águas nos estudos sobre participação, ao incluir as modalidades não convencionais (BRADY, 1999, VAN DETH, 2001, VERBA, SCHLOZMAN \& BRADY, 1995) ${ }^{32}$. Em termos metodológicos também realizou inovações, ao articular a dimensão das atitudes e comportamento na criação de uma escala de participação não convencional. Em que pese tais avanços, o estudo sofreu críticas principalmente em função de uma interpretação homogeneizante dos atos participativos (BRADY, 1999, p. 754) e pelo fato de ser obscuro quanto às distinções internas às distintas modalidades (TEORELL, TORCAL \& MONTERO, 2007, p. 334). Outra crítica é quanto à própria distinção entre participação convencional e não convencional, que, se era uma denominação adequada para o contexto dos anos de 1970, já não seria apropriada para diferenciar as modalidades de participação hoje, pois a maioria dos atos "não convencionais" daquele contexto, teriam se "convencionalizado" nas realidades das democracias do século XXI (VAN DETH, 2001, DALTON, SICKLE \& WELDON, 2009). Um último comentário sobre Political Action é que o estudo foi replicado em 1979 - 1981, em pesquisa realizada em três países (Holanda, Alemanha e Estados Unidos) e cujos resultados estão em Jennings et alli (1990).

A grande inovação posterior a Political Action é sem dúvida o trabalho de Verba, Schlozman e Brady (1995) $)^{33}$. Tal trabalho incorpora a participação não convencional como modalidade de participação, mas também inclui modalidades não enderaçadas ao "governo". Exemplo são as formas "sociais" de participação, como o "voluntariado". Como bem destaca Van Deth (2001), essa nova ampliação das medidas de participação foi resultante do revival dos argumentos Tocquevilleanos, em especial pelas robustas evidências empíricas apresentadas pelos trabalhos de Robert Putnam (1996, 2002 e 2003). Nas palavras de Van Deth:

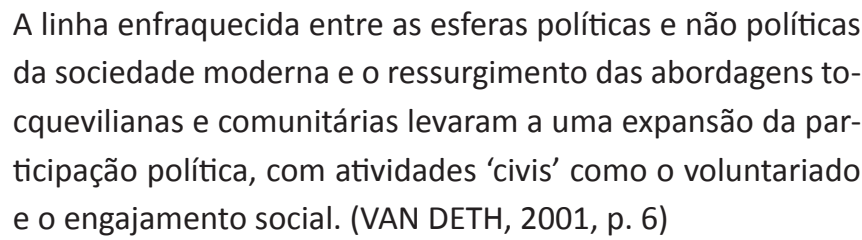

Nesse sentido, Verba, Schlozman e Brady (1995a) vão desenvolver aquilo que foi denominado de modelo do "voluntarismo cívico", onde o processo de engajamento político é visto como mediado pela relação entre custos e recursos, sendo a participação resultante das motivações e das capacidades dos indivíduos para participar, as quais são mediadas pelas "redes de recrutamento" 34 . Os recursos mais significativos seriam o tempo, o dinheiro e as "habilidades" individuais.

Em termos de classificação das modalidades de participação, o estudo em 
questão, ao incorporar novas modalidades, chega a uma tipologia composta por nove elementos, reafirmando a multidimensionalidade do fenômeno. Tais dimensões seriam: votar, trabalhar em campanhas políticas, contribuição para campanhas, contato com oficiais, protesto, trabalho informal na comunidade, membro de um conselho local, filiação a uma organização política e contribuição a uma causa política. O esquema classificatório, com seus correlatos de requerimentos de recursos, informações e variação do volume estão apresentadas na tabela abaixo ${ }^{35}$.

Tabela 5 - Os atributos das atividades políticas

\begin{tabular}{|c|c|c|c|}
\hline Atividade & $\begin{array}{c}\text { Capacidade para } \\
\text { transmitir informa- } \\
\text { ção }\end{array}$ & Variação no volume & Requerimentos \\
\hline Voto & Baixo & Baixo & Tempo \\
\hline $\begin{array}{c}\text { Trabalho de cam- } \\
\text { panha }\end{array}$ & Misto & Alto & Tempo e Dinheiro \\
\hline $\begin{array}{c}\text { Contribuição para } \\
\text { campanha }\end{array}$ & Misto & Alto & Dinheiro \\
\hline Protesto & Alto & Médio & Tempo, Habilidades \\
\hline $\begin{array}{l}\text { Contato com agen- } \\
\text { tes públicos }\end{array}$ & Alto & Médio & Tempo \\
\hline $\begin{array}{c}\text { Trabalho informal } \\
\text { na comunidade }\end{array}$ & Alto & Alto & Tempo, Habilidades \\
\hline $\begin{array}{c}\text { Membro de um } \\
\text { clube político local }\end{array}$ & Alto & Alto & Tempo, Habilidades \\
\hline $\begin{array}{c}\text { Filiação a uma } \\
\text { organização parti- } \\
\text { dária }\end{array}$ & Misto & Alto & $\begin{array}{l}\text { Tempo, Habilida- } \\
\text { des, Dinheiro }\end{array}$ \\
\hline $\begin{array}{c}\text { Contribuição a uma } \\
\text { causa política }\end{array}$ & Misto & Muito alto & Dinheiro \\
\hline
\end{tabular}

Fonte: Verba, Scholozman \& Brady (1995a, p. 48)

O trabalho de Verba, Scholozman e Brady (1995a) pode ser considerado o maior esforço teórico e metodológico no âmbito da construção de uma teoria da participação política empiricamente orientada. Seus resultados têm tido desdobramentos tanto em novas pesquisas empíricas (VERBA, BARNS \& SCHLOZMAN, 2001; LIPHART, 1997), como também no debate normativo ocorrido no âmbito da disciplina (VERBA, 2006; DAHL, 2006) ${ }^{36}$. em especial, Inglehart e Welzel (2009); Dalton e Klingemann (2007), Topf (1995a e 1995b), Norris (2002; 2007), Clark e Hoffman (1998), Dalton (2002).

33. Como destaca Brady (1999, p. 758), tal estudo também foi replicado na Estônia e Rússia.

34. Uma discussão sobre o modelo teórico proposto encontra-se em Verba, Scholozman e Brady (1995b).

35. As modalidades de participação política classificadas por Verba, Scholozman e Brady (1995a) são extraídas de um conjunto formado por 32 perguntas do questionário elaborado no contexto do projeto Citzen Participation.

36. O volume 91, número 2, de 1996, da American Political Science Review, dedicou várias resenhas à Voice and Equality. 
37. Ronald Inglehart tem coordenado um dos mais ambiciosos projetos intelectuais no âmbito das ciências sociais. Tratase do World Value Survey, cujos dados já compreendem amostragem representativa de mais de $85 \%$ da população mundial. Para maiores informações ver www.worldvaluessurvey.org/.

38. Para maiores esclarecimentos sobre a teoria do pósmaterialismo e sua validade empírica, considerando a realidade latino-americana, ver Ribeiro e Borba (2010).
Especificamente no âmbito da pesquisa empírica, o estudo reafirmou o conteúdo multidimensional da participação e promoveu uma articulação daquilo que a literatura tradicionalmente tratava de forma diferenciada, que é relação entre participação política e participação social. Por outro lado, essa ampliação do escopo do conceito e dos indicadores de participação política deu margem para críticas como as de Van Deth (2001), ao destacar que a incorporação de novos elementos (modalidades) classificados como "políticos" nos estudos de participação - que ocorreu de forma contínua ao longo dos últimos anos -, se, por um lado, é um indicativo de que os fenômenos em questão são historicamente constituídos e, dessa forma, tal ampliação seria um sinal de vitalidade desse campo de pesquisas em sua capacidade de acompanhar o desdobramento daquilo que acontece na história. Por outro, essa ampliação conceitual é problemática, pois coloca o risco de se perder a referência sobre as linhas demarcatórias daquilo que seria um conceito mínimo de participação política. O risco, nesse caso, como afirma Van Deth (2001), é sua ampliação rumo a uma "teoria do tudo"!

Por fim, cabe destacar que, para além das classificações existentes, outros autores têm proposto denominações mais específicas para as modalidades de participação, que, de alguma maneira, são contempladas nos estudos anteriores. Nos limitaremos a mencionar tais estudos. O primeiro deles é do Ronald Inglehart e Christian Welzel (2009). Como se sabe, o autor foi um dos colaboradores de Political Action (1978) e tem utilizado a distinção entre participação convencional e não convencional em seus estudos ${ }^{37}$. Porém, Inglehart também tem feito uso de outras denominações, como aquela que diferencia as modalidades de participação segundo sua relação com as elites da sociedade. Assim, teríamos as ações "elite directed", onde os cidadãos participam através de organizações hierárquicas, como os partidos, sindicatos, etc. Tais modalidades, segundo o autor, estariam em declínio em praticamente todos os contextos democráticos. Já as ações "elite challenging", seriam aquelas formas de ação diretas, não institucionalizadas, cujos exemplos mais representativos seriam as realizadas através de protestos ou boicotes. Segundo a teoria do inglehartiana, tais ações, estariam em ascensão, sendo um dos indicadores da emergência de valores pós-materialistas (INGLEHART \& WELZEL, 2009, INGLEHART \& CATTERBERG, 2002) ${ }^{38}$. Do mesmo modo, Pippa Norris (2007) propõe a diferenciação entre ações "cause oriented", exemplificada também pelos movimentos sociais e as atividades de protesto, e aquelas "citizen oriented" cujos exemplos seriam a política partidária e a participação em eleições. Por fim, ainda nessa diferenciação entre "novas" e "velhas" modalidades de participação, temos aquela proposta por Cabral (2009) entre "automobilização" e participação através de pertencimento a organizações, ou "participação associativa". A diferenciação entre as duas modalidades seria equivalente àquela realizada por Inglehart e Norris, automobilização sendo equivalente à "cause oriented" e "elite-challenging". 


\section{b) Novas Tipologias}

Concomitantemente a essas grandes pesquisas desenvolvidas sobre participação, foram-se estabelecendo novas iniciativas metodológicas visando proceder uma melhor compreensão sobre como as diferentes modalidades de participação se articulam entre si, no sentido de precisar melhor o argumento de que a participação é um fenômeno multidimensional, bem como a validar e/ou refutar as classificações já existentes na literatura.

Um dos primeiros esforços, nesse sentido, foi feito por Sabucedo e Arce (1991). Seu ponto de partida é a afirmação da necessidade de definição e classificação corretas dos fenômenos sociais. Os autores questionam se uma análise mais detalhada sobre os vínculos entre as distintas modalidades de participação não levaria a ampliar o seu diagnóstico de um fenômeno heterogêneo, possibilitando-se estabelecer novas classificações (p. 94).

Para verificar a questão, realizam uma investigação empírica orientada para a busca da identificação da representação que os próprios atores fazem sobre as relações entre suas diferentes atividades políticas. Seus dados empíricos foram oriundos de um survey realizado com 77 estudantes da Universidade Santiago de Compostela ${ }^{39}$.

Através da aplicação da análise de cluster, utilizando-se de métodos hierárquicos, verificou-se que as variáveis formaram dois grupos que internamente se dividiam em dois subgrupos cada. Um grande grupo formado pelas atividades "legais" e outro por atividades "ilegais". O primeiro tem uma divisão interna, agrupando (1) as atividades de persuasão e influência que acontecem durante as campanhas eleitorais e "são evidentemente afetadas pela filiação partidária" - participar de campanhas políticas e tentar convencer outros sobre o voto (p. 99). Em (2) estão agrupadas as atividades de envolvimento político em formas distintas e incluiu o "voto", "escrever para jornais", "participar de protestos autorizados" e "participar de greves autorizadas". O segundo cluster (atividades ilegais) também produziu dois subgrupos. Um deles que agrupou as atividades consideradas violentas (atentar contra a propriedade e violência armada) e um segundo que agrupou modalidades não violentas: boicotes, greves não autorizadas, protestos não autorizados, ocupação de prédios e interrupção do tráfego de veículos.

O estudo permitiu aos autores proporem uma forma de classificação para as modalidades de participação que denominam de "persuasão eleitoral", "participação convencional", "participação violenta" e "participação direta e não violenta". Segundo eles, tal classificação permitiria sair da "arbitrariedade" das distinções comumente apresentadas na literatura. Além do mais,
39. Foram usados 30 tipos de participação como estímulo, os quais produziram 78 pares (de relações). Com esses pares foi construída uma escala de nove pontos para avaliar a dissimilaridade entre cada par de estímulos. A partir disso foi aplicado o standard rotating method para ordenar tais pares de estímulos. Adicionalmente, os sujeitos foram interrogados sobre uma escala de julgamento de 29 pontos e, finalmente, se posicionaram numa escala de identificação ideológica ( $p$. 95). 
40. Trata-se do projeto Citizenship, Involvement, Democracy (CID), cujas pesquisas desenvolvem-se nos Estados Unidos (http:// www8.georgetown. edu/centers/cdacs/ cid/) e na Europa, através da articulação entre pesquisadores de várias universidades. Para maiores informações, ver http:// www.mzes.uni-mannheim.de/projekte/ cid/.

41. O questionário pergunta se, nos últimos doze meses, o respondente participou de: (a) Voto: votou em eleições parlamentares, se absteve do voto como forma de protesto; (b) Envolvimento em partidos políticos: membro de partido participou em atividades partidárias, doou dinheiro, prestou trabalho voluntário; (c) Ações para influenciar a sociedade: contato com políticos, contato com organizações, contato com servidores públicos, trabalhou num partido político, trabalhou numa ação política de grupos, trabaIhou em outras organizações, usou ou exibiu algum crachá, assinou um abaixoassinado, participou de demonstrações públicas, participou de greve, boicotou determinados produtos, comprou certos produtos, doou dinheiro, recolheu dinheiro,
(...) nossos resultados mostram que há uma distinção precisa entre diferentes formas de participação violenta e diferentes formas de participação não violenta. Particularmente, acreditamos ter identificado distinções importantes dentro da categoria que tradicionalmente tem sido vista como 'não convencional' ou 'ilegal'. (SABUCEDO \& ARCE, 1991, p. 100-101)

Entendemos que a importância do trabalho de Sabucedo e Arce (1991) se deu, sobretudo, no sentido de chamar a atenção para distinções analíticas no tocante às modalidades de participação. Acreditamos, assim, que o mérito do trabaIho está essencialmente no plano metodológico, ao utilizar técnicas de análise que posteriormente foram incorporadas a outros estudos classificatórios. Outra contribuição está no fato de recolocarem a ideia de participação não convencional num outro plano, cuja distinção se daria no caráter violento ou não da ação. Além disso, transferem algumas modalidades tidas como não convencionais para a "convencionalidade", como escrever a um jornal e participar de protestos e greves autorizadas. Os limites do trabalho estão relacionados, principalmente, ao universo pesquisado (estudantes universitários), um grupo bastante restrito e homogêneo, em geral, com atitudes e padrões vinculados à dimensão geracional (DALTON, 2008), o que impossibilita qualquer tipo de generalização de tal classificação.

Um trabalho mais recente que se detém, especificamente, na proposta de uma tipologia classificatória para as modalidades de participação é o de Teorell, Torcal e Montero (2007). Os autores, após uma exaustiva análise sobre modelos existentes e utilizando dados do CID Survey ${ }^{40}$, abordam um grande conjunto de modalidades de participação e ação políticas, divididas em atividades relacionadas ao voto, partidos, atividades de protesto e também o uso político da Internet ${ }^{41}$.

Sua proposta de tipologia toma como ponto de partida o diagnóstico de que os ativistas optam por determinadas modalidades de participação, de modo que “(...) atividades de cluster específicas formam uma dimensão distinta de participação política" (2007, p. 340). Para realizar a classificação, procedem de modo a organizar as modalidades de participação a partir de duas dimensões: o canal de expressão e o mecanismo de influência. O canal de expressão pode ser utilizado através do uso dos canais de representação (voto e a atividade partidária) ou extrarrepresentação (protesto e a "consumer participation"). Uma modalidade mista de expressão seria o "contato político". Já o mecanismo de influência poderia se dar através de estratégias de "saída" (voto, a "consumer participation" ${ }^{\prime 42}$ ) e ou "voz"43 (atividade partidária, protesto e contato). O resultado é uma matriz, que é apresentada abaixo: 


\begin{tabular}{|c||c|c|c|}
\hline \multicolumn{2}{|c|}{} & \multicolumn{2}{c|}{ Canal de Expressão } \\
\cline { 2 - 4 } & Representacional & $\begin{array}{r}\text { Extra Representacio- } \\
\text { nal }\end{array}$ \\
\hline \multirow{2}{*}{$\begin{array}{c}\text { Mecanismo de } \\
\text { Influência }\end{array}$} & "Saída" & Voto & $\begin{array}{c}\text { Consumer Participa- } \\
\text { tion }\end{array}$ \\
\cline { 2 - 4 } & "Voz" & $\begin{array}{c}\text { Atividade Partidá- } \\
\text { ria } \\
\text { (non-targeted) }\end{array}$ & $\begin{array}{c}\text { Atividade de Protesto } \\
\text { (non-targeted) }\end{array}$ \\
\hline & \multicolumn{2}{|c|}{$\begin{array}{c}\text { Contato } \\
\text { (non-targeted) }\end{array}$} \\
\hline
\end{tabular}

Fonte: adaptado de Teorell, Torcal e Montero (2007, p. 341)

Sua tipologia, como os próprios autores reconhecem é bastante próxima daquela de Verba e Nie (1972), porém, incluindo os canais extrarrepresentativos de expressão politica, como o protesto ou o "consumer participation". O teste empírico da tipologia, foi conduzido com os dados dos 13 países participantes do CID Survey, através da técnica da "análise dos componentes principais". Os resultados confirmam a validade da classificação para todos países, com exceção de Portugal ${ }^{44}$, cujo modelo produziu um agrupamento distinto para as variáveis, o que leva os autores a concluírem que:

O fato de que o padrão dimensional é quase idêntico nesses conjuntos, em outros aspectos distintos, de esferas políticas, econômicas e culturais é um argumento forte a favor da medição da equivalência entre nossos quatro modos de atividade. Este resultado corrobora o argumento de que a multidimensionalidade da participação política está imbricada na natureza particular de cada modo de participação e não responde a configurações institucionais específicas de uma nação. (p. 348)

A classificação apresentada acima, elaborada por Teorell, Torcal e Montero (2007) pode ser considerada uma das mais sofisticadas construções metodológicas no campo da sociologia da participação, seja pela complexidade do conjunto de questões incluídas no CID Survey (25 perguntas), seja por incorporar novas modalidades de participação, como é o caso da "consumer participation". Além disso, avança na compreensão do caráter multidimensional do fenômeno, ao separar as modalidades conforme seus canais de expressão e os mecanismos de influência, cuja diferença interna se relaciona aos custos envolvidos nos diferentes atos. Por fim, tais indicadores foram validados nos testes empíricos realizados. O limite do trabalho está no fato de se concentrar empiricamente contactou a mídia, participou em protestos ilegais, reuniões políticas, outras; (d) uso da internet para influenciar a sociedade. Ao todo, são 28 perguntas no questionário que são relacionadas para desenvolver sua tipologia da participação (VAN DETH, 2001).

42. A incorporação do "consumer participation" como uma modalidade de participação política está relacionada às atividades de boicote ao consumo de determinados produtos, por razões de ordem ecológica ou social. Verificamse também campanhas de estímulo a determinados hábitos alimentares e ao consumo de determinados tipos de produtos (p. ex. os alimentos orgânicos). Sobre o tema, ver Micheletti (2005).

43. Os autores fazem uso da clássica tipologia de Albert Hirschmann (1970) que estuda o comportamento de consumidores e cidadãos a partir das estratégias de "saída", "voz" ou "lealdade".

44. O caso de Portugal, segundo os autores, "a mobilização partidária parece obstruir a presença de dimensões distintas da atividade de protesto e da participação 
do consumidor" ( $p$. 355).

45. Disponível em http://cinefogo. cuni.cz/

46. O ISSP (International Social Survey Programme) é um programa contínuo de pesquisas comparativas, com amostragens nacionais. As pesquisas estão organizadas em módulos fixos e módulos que são incluídos em rodadas específicas. Para maiores detalhes, ver http:// www.issp.org/page. php?pageld $=4$ na realidade das democracias europeias, onde, em que se pese as diferenças entre os países, não consegue captar muitas outras diferenças de contexto. Os próprios autores (p. 343) reconhecem tal limite quando comparam sua tipologia àquela formulada por Verba e Nie (1972).

Um terceiro conjunto de trabalhos foi produzido no âmbito de uma discussão realizada no Workshop "Methodological Challenges in Cross-National Participation Research" ${ }^{45}$. Do conjunto de trabalhos apresentados, três deles nos são de particular importância. Comecemos por Mitja Hafner-Fink (2009) em "Using cluster analysis to discover political participation typologies in a comparative context". Utilizando-se de dados do ISSP $(2004)^{46}$, o autor vai buscar construir não propriamente uma tipologia da participação, mas dos "cidadãos que praticam várias formas de participação política” (HAFNER-FINK, 2009, p. 2). Para tanto, faz uso da técnica da análise de cluster (hierarchical cluster analysis) e principal components analysis. O estudo faz uso de várias modalidades de participação, divididas em três níveis analíticos:

1. Atividade Política, dividida em a) comunicação (contato com políticos, contato com os meios de comunicação, participação em fóruns da Internet); b) participação direta em ações (boicotes, participação em demonstrações, participação em comícios); e c) suporte à projetos políticos (abaixo-assinado, doações de dinheiro).

2. Membro de Organizações, dividido em a) partidos, b) sindicatos e organizações profissionais, c) organizações religiosas e d) sociedades e organizações voluntárias.

3. Interesse em Política, dividido em a) um indicador de interesse em política e b) dois indicadores de discussão de assuntos políticos.

Num primeiro momento, o autor procedeu ao teste da classificação das modalidades, buscando verificar se a distinção entre participação institucionalizada versus participação individualizada se verificava empiricamente. Hafner-Fink identificou que as três formas de comunicação se agruparam com participação em demonstrações e comícios. Já boicotes, petições e doações produziram outro agrupamento próprio. Com esses dois grupos de atividades políticas, ele parte para uma segunda análise, incluindo na análise de cluster, a participação em organizações e o interesse por política. Com isso, o autor chega a uma nova tipologia da participação (agora a partir dos grupos de indivíduos). Os resultados apontam para diferentes agrupamentos quando os dados são analisados por país. Após vários testes, chega a uma classificação mais parciomoniosa, formada pelas seguintes categorias: praticantes de atividades individualizadas; praticantes de atividades políticas partidárias; pertencentes a partidos políticos 
e pertencentes a outras organizações. Além desses, cria a categoria dos "excluídos/observadores". Internamente a tais categorias são criados subagrupamentos e os dados são apresentados e agrupados por país (p. 11).

Trata-se de uma análise bastante complexa, que articula a dimensão da ação política com a dimensão organizacional da participação (BRADY, 1999). Assim, de modo inverso a Teorel, Torcall e Montero (2007), que buscam construir sua tipologia a partir de uma estratégia dedutiva, Hafner-Fink (2009) articula dedução e indução. A primeira quando busca articular as modalidades de participação em "institucionalizadas" e "individualizadas". A segunda, ao verificar como os grupos de indivíduos se distribuem entre os distintos campos para aí construir sua tipologia do engajamento (que se dá entre diferentes combinações entre o cidadão "alienado" e aquele que combina participação institucionalizada com participação partidária).

O limite de tal análise é que ela não consegue produzir uma tipologia propriamente dita dos atos políticos, mas uma tipologia dos ativistas políticos. Com isso, cai-se novamente na crítica que já era feita ao trabalho de Barnes e Kaase (1979), de tratar a participação como um fenômeno unidimensional (mesmo que esse não seja o objetivo do autor).

Por fim, temos o trabalho de Albacete $(2009)^{47}$, que se debruça sobre a tentativa de construir medidas equivalentes de participação política que sejam úteis para a pesquisa comparativa ${ }^{48}$. Seu ponto de partida é que a comparação entre países exige a construção de medidas equivalentes entre as variáveis em análise (PRZEWORSKI \& TEUNE, 1970, VAN DETH, 2009). Propõe, dessa forma, comparar a "estrutura latente" das modalidades de participação, utilizando, para isso, a escala de Mokken (MSA), a qual permite a ordenação das diferentes variáveis, a partir de critérios predeterminados, onde as dimensões em teste são verificadas através de um processo cumulativo de análise ${ }^{49}$. 0 interessante do uso de tal escala é que ela possibilita fazer a equivalência de dados para pesquisas aplicadas em contextos distintos. Dessa forma, consegue-se proceder com a comparação a partir de "medidas equivalentes" (sem ter que usar as variáveis relacionadas às modalidades de participação, de forma individualizada).

Os resultados do estudo com o conjunto de países da amostra indicaram a existência de duas escalas de participação: uma que inclui formas convencionais e outra que compreende as atividades de protesto. A escala é bastante semelhante àquela de Barnes e Kaase (1979) e, em que pese o autor defender uma visão multidimensional da participação, seus resultados são bastante reducionistas, ao considerar a estrutura e as bases da participação como compostas de apenas duas modalidades (formas institucionalizadas versus atividades de protesto).
47. O uso da escala de Mokken já havia sido aplicado por Van Deth (1986) num estudo dedicado à mesma temática. Nesse trabalho, Van Deth (1986) chega à conclusão de que seria pouco apropriado o uso da distinção entre participação convencional e não convencional, pois os resultados dos testes empíricos apontavam para uma unidimensionalidade na escala de participação. A distinção que o autor considera mais apropriada seria aquela entre atividades direcionadas ao governo e atividades não direcionadas ao governo (como, p. ex. as atividades políticas dos sindicatos).

48. A discussão sobre a importância de medidas equivalentes nos estudos de participação é salientado por Van Deth (1986), ao lembrar que determinadas perguntas (que são aplicadas de maneira identica nos diferentes países) têm significados distintos, dependendo do contexto linguísitico em que são aplicadas. Em suas palavras: "O conceito germânico de Biirgerinitiative, por exemplo, tem muito em comum com o que se chama inspraak, em holandês. Ambos referem-se a modos de participação mais ou 
menos novos e não eleitorais. Mas os conceitos certamente não são idênticos. Como não há um correspondente literal em holandês para o Biirgerinitiative germânico, não se pode fazer uma comparação dos níveis de participação nesses países quando são usadas traduções literais. Desse modo, ou abandonamos todas as referências a modos de participação específicos de uma nação ou período, ou tentamos estabelecer instrumentos equivalentes em vez de idênticos".

49. Segundo Albacete (2009, p. 5-6) a MSA é uma combinação de um modelo de medição e um procedimento padrão de análise individual de cada resposta a um conjunto de itens que são projetados para ser indicadores da dimensão latente de uma única variável. Ela se diferencia da análise de componentes principais (PCA) ou análise de confiabilidade, pois os dois primeiros métodos pressupõem que os itens podem ser considerados paralelos, ou seja, ter a mesma frequência de distribuição (a mesma média e desvio padrão), o que torna difícil a interpretação dos dados quando se faz análise fatorial com dados dicotômicos (p. 6). Já na

\section{Considerações Finais}

O balanço da literatura, apresentado nas páginas acima, nos permitiu chegar a algumas constatações com relação ao que se passa no universo dos estudos sobre participação política, em especial no que se refere às propostas classificatórias.

Em primeiro lugar, é inegável o crescimento quantitativo e qualitativo desse campo de pesquisas. Desde 1965, quando surge o trabalho de Milbrath, ampliaram-se constantemente o número de pesquisadores envolvidos na temática, a quantidade de publicações e o número de bases de dados que incluem baterias de questões sobre modalidades de participação. Hoje, praticamente todas as grandes pesquisas comparativas na área de opinião pública possuem módulos fixos dedicados ao tema da participação ${ }^{50}$. Nesse caso, considerandose apenas aquilo que é coberto pelo WVS, teríamos dados longitudinais sobre participação, cobrindo mais de $85 \%$ da população mundial. Outro indicador da vitalidade da área é que boa parte dos Handbooks na área de Ciência Política tem dedicado ao menos um capítulo sobre a temática (LIPSET, 1995; GOODWIN \& KLINGEMANN, 1996; DALTON \& KLINGEMANN, 2007; BOIX \& STOCKES, 2007; ROBINSON, 1999, KATZNELSON \& MILNER, 2002).

Tal crescimento da área, veio acompanhado da crescente sofisticação dos instrumentos de coleta $^{51} \mathrm{e}$ das técnicas de análise dos dados, de modo a que temos evidências as mais robustas sobre determinantes individuais e contextuais da participação política nas mais diferentes modalidades de participação. Outro elemento também a ser destacado é que a pesquisa na área foi ampliando o conteúdo do próprio conceito de participação, de modo a incorporar novas modalidades que foram surgindo no âmbito das democracias (VAN DETH, 2001).

Em que pese tais avanços, a continuidade das pesquisas sobre participação coloca a necessidade de se resolver alguns graves problemas. O primeiro deles é de ordem metodológica. Como já destacamos acima, são diversos os empreendimentos comparativos na área de participação; o problema é que não existe uma unificação de linguagem, seja na redação da maioria das perguntas que constituem os surveys (BRADY, 1999), seja nos próprios indicadores do que deve ser considerado como participação (VAN DETH, 2001). Tais situações têm dificultado o avanço de comparações (longitudinais ou entre países) e provocado sérias distorções na interpretação de alguns resultados das pesquisas. Um exemplo é a controvérsia em torno do declínio ou não das taxas de comparecimento eleitoral nos Estados Unidos. As pesquisas têm chegado a resultados distintos, alguns deles com divergências brutais em relação às estatísticas oficiais (BRADY, 1999).

Acreditamos, porém, que o problema mais grave seja de ordem teórica. Nesse 
sentido, parece que a crítica feita por Johnson (2005) em relação à tradição de pesquisas sobre cultura política pode ser transferida aos estudos sobre participação (cuja origem intelectual é mesma, diga-se de passagem). Para esse autor, tal tradição careceria propriamente de uma teoria, tendo-se preocupado muito mais com as estratégias de coleta e análise dos dados, do que na resolução de problemas conceituais. É viável supor que boa parte das discordâncias classificatórias que tivemos a possibilidade de resenhar ao longo desse texto estão relacionadas a problemas conceituais não resolvidos.

Como derivação desse problema, assistimos ao que Huxtin e Denk (2009) denominam de o "problema da caixa-preta" 52 nos estudos sobre participação. Os autores utilizam tal metáfora, pois afirmam que apesar da literatura ter conseguido acompanhar as transformações vivenciadas pelo seu objeto de investigação, em especial aquelas ligadas à emergência das modalidades não convencionais, o tratamento analítico que se deu a tal questão foi bastante precário, pois os estudos se limitaram a ampliar as classificações e colocar os indivíduos em algumas das "caixas"; porém, pouco se detiveram a descobrir o que se passaria dentro delas. Os estudos têm mapeado quem são os cidadãos que participam, onde participam e a intensidade de sua participação, mas pouco dizem sobre como os indivíduos fazem suas escolhas (HUXTIN \& DENK, 2009 p. 12). Concluem os autores, que o privilégio de determinadas medidas comparativas, num crescente repertório de ações políticas, se deu à custa de um refinamento qualitativo das dimensões da participação. Como alternativa, apontam um caminho metodológico no sentido de explorar as trajetórias do engajamento político (como se deu a entrada, os antecedentes, as condições, experiências e resultados) (p. 17) e destacam os exemplos de algumas pesquisas que estão trilhando tal caminho. Entre os quais, o de Whiteley e Seyd (2002), num estudo sobre militância partidária na Grã-Bretanha, ao construir uma escala de intensidade de participação, com oito itens, que representam três dimensões (contato político, campanhas e representação), através do uso de um modelo de equações estruturais (apud HUXTIN \& DENK, 2009), ou o do Stolle, Micheletti e Hooghe (2005), que aplicam a análise fatorial para construir um índice de "political consumerism", baseado em itens como conhecimento, comportamento e motivação, frequência e hábito.

O diagnóstico de Hustin e Denk (2009) parece ser coerente com certo desconforto que perpassa a literatura sobre participação, no sentido de que esta tem se estruturado em torno de propostas classificatórias e tipologias que não têm conseguido captar a complexa dinâmica que envolve os atos participativos, desde o recrutamento dos ativistas, até o resultado produzido pelas ações, principalmente, no sentido de identificar o que se passa dentro de cada uma das dimensões e modalidades de participação (as "caixas pretas").

Comungamos com suas preocupações e acreditamos na importância de
MSA, "Presume-se que cada sujeito tenha um valor certeiro e esconhecido na dimensão latente. Para cada item, a probabilidade de uma resposta positiva aumenta com essa variável desconhecida. Nesse caso, presume-se que cada respondente possa ser colocado em uma escala de participação política. A probabilidade de um indivíduo ter participado de uma ação específica - por ex., uma manifestação política - será maior se ele tiver participado de uma atividade menos exigente (ou mais fácil), tal como votar. Em segundo lugar, a MSA permite uma abordagem confirmatória, ou seja, avaliação de um conjunto de itens como uma escala cumulativa. Assim sendo, poderemos examinar as propriedades de uma tal escala. Como resultado, poderemos testar a pressuposição de que os diversos modos de participação podem ser ordenados de ações mais fáceis para mais difíceis, em uma escala departicipação política. Finalmente, a MSA oferece a possibilidade de testar a escala (ou escalas) em diversos grupos e, desse modo, verificar se o instrumento de medição é válido em diferentes nações" (p. 6). 
Para maiores detaIhes e aplicações do método na análise política, ver Mokken (1971) e Van Schuur (2003) e Van Deth (1986).

50. Como exemplos, temos o European Social Survey (http://www.atitudessociais.org/ess/), o World Value Survey (www.wvs.org), O ISSP (http://www. issp.org/) o CID Survey (http://www8. georgetown.edu/ centers/cdacs/cid/) e Comparative Study of Electoral System (http://www.cses. org/).

51. Por exemplo, com a inclusão de pesquisas tipo painel, de modo a entrevistar o mesmo indivíduo em dois momentos ou a inclusão de abordagens qualitativas, como os experimentos e grupos focais.

52. A metáfora da caixa-preta "referese à observação de que tipos/modos de participação ainda são tratados como uma realidade unitária que não precisa ser analiticamente decomposto em mais detalhes" ( $p$. 14).

53. Dois trabalhos que seguem nessa direção, de articular a dimensão do contexto com os atributos individuais, são os de Dalton, Sickle e Weldon (2009) e Della Porta (2008). estreitar o diálogo com duas outras tradições de pesquisas, que poderiam ajudar nessa empresa. Uma delas, seria com os esforços empreendidos em torno da "sociologia do militantismo" (FILLIEULE, 2001) que tem se dedicado aos mecanismos, recursos e trajetórias que constituem o "capital militante". Outro tipo de abordagem que consideramos ser apropriada de inserir no diálogo com os estudos de participação é aquela relacionada aos estudos da "política contenciosa" (TARROW, 2009; TILLY \& TARROW, 2007), que têm demonstrado como a ação política é fruto de atributos individuais relacionados a determinadas características do contexto, o qual define as possibilidades de manifestação de determinados repertórios da ação coletiva ${ }^{53}$. Nos parece que a iniciativa recente de constituição de uma rede de pesquisas em torno do desenvolvimento de metodologias e de realização de estudos empíricos sobre o engajamento político parece ser um sinal positivo em torno do avanço das pesquisas na área ${ }^{54}$.

Acreditamos, também, que o avanço nas pesquisas sobre participação e suas modalidades implica em ampliar os contextos onde são desenvolvidas tais análises. É importante salientar que nenhuma das propostas de classificação que listamos acima tomou como parâmetro empírico os países da América Latina ou África, cujos processos de constituição política têm profundas variações diante do contexto europeu e norte-americano. Lembramos da necessidade de verificações quanto à pertinência das referidas classificações para esses contextos. Resultados exploratórios de testes de agrupamentos de modalidades de participação (RIBEIRO \& BORBA, 2010a) apontaram para resultados relativamente diferentes dos verificados acima, quando se consideram especificamente os países da América Latina.

Por fim, espera-se que as pesquisas passem a incluir outras modalidades de participação nos seus modelos. Mais especificamente, nos referimos àquelas instituídas pelo Estado. Tais modalidades foram estudadas apenas como parte do contexto de instabilidade política dos países em desenvolvimento (HUNTINGTON \& NELSON, 1976). Nos últimos anos, porém, temos assistido a novas experiências de participação instituídas pelo Estado (no contexto dos países desenvolvidos e subdesenvolvidos), as quais têm sido muito pouco estudadas sob as perspectivas aqui resenhadas (SCHLOZMAN, 2002). Além disso, na realidade brasileira, tais modalidades (nos referimos em especial aos Orçamentos Participativos) têm se constituído numa importante forma de mobilização política para contingentes significativos da população, em especial para aqueles menos centrais na estrutura social (RIBEIRO \& BORBA, 2010b). Acreditamos que agregar novas modalidades aos estudos de participação, promoveria significativos ganhos analíticos. 
Abstract: In the face of the intense ongoing theoretical and methodological debate about political participation within Political Sociology, our purpose is to map the international literature that deal with proposals of classificatory typologies to be applied on the modalities of political participation. The outcomes of the debate are of paramount importance for the discipline to strengthen its analytical capability to grasp the transformations occurring in the universe of participation. The paper ends with a set of methodological proposals for the advancement of research studies in the field.

Keywords: Political Participation, Political Culture, Comparative Politics.
54. Estamos nos referindo ao projeto "Caught in the act of protest: contextualizing contestation (CCC)", Financiado pela European Science Fundation (2008). Disponível em www.protestsurvey.eu

\section{Referências}

ALBACETE, G. M. G. Towards equivalent measures of political participation. Paper prepared to Cinefogo. WP 11 WORKSHOP: "Methodological Challenges in Cross-National Participation Research". The Hague, 16-19 January, 2009. Disponível em http://cinefogo.cuni.cz/index.php?\&l=0\&w=16\&id_event=92. Acesso em novembro de 2010.

ALDRICH, J. H. "Racional choice and turnout". American Journal of Political Science. 37, 1993, p. 246-278.

ALMOND, G.A.; VERBA, S. The civic culture: Political attitudes and democracy in five nations. Newbury Park: Sage, 1989.

BARNES, S.H.; KAASE, M (org.). Political action: Mass participation in five Western democracies. Beverly Hills: Sage, 1979

BERELSON, B. R., LAZARSFELD, P.; MCPHEE, W. Voting: A Study of OpinionFormation in a Presidential Campaign. Chicago: University of Chicago Press, 1954.

BORBA, J. "Apresentação". In: Scherer-Warren, I. e Lüchmann, L. H. . (Org.). Movimentos Sociais e participação: abordagens e experiências no Brasil e na América Latina. 1 ed. Florianópolis: Editora UFSC, 2011, v. 1, p. 9-16.

BORBA, J "Participação política como resultado de instituições participativas: oportunidades políticas e o perfil da participação". In: Pires, R. R. C. . (Org.). Efetividade das instituições participativas no Brasil: estratégias de avaliação. 1 ed. Brasília: Ipea (Diálogos para o Desenvolvimento), 2011, v. 7, p. 65-76.

BOIX; STOCKES, D. The oxford handbook of comparative politics. Oxford: Oxford University Press, 2007.

BOOTH, J.; SELISON, M. A. Political participation in Latin America. Vol. 1: Citzen and State. Holmes \& Meyer Publishers, 1978. 
BRADY, H. E. "Political participation". In: Robinson, J. P. (eds.), Measures of political attitudes. San Diego, CA: Academic Press, 1999, p. 737-801.

BURNS, N.; SCHLOZMAN, K. L; VERBA, S. The private roots of public action: gender, equality, and political participation. Cambridge, Massachusetts, London, Engalnd, 2001.

CABRAL, M. V. "Civic and political participation: a new culture shift? - evidence from 12 countries". Conferência proferida no XIV Congresso da Sociedade Brasileira de Sociologia. Rio de Janeiro, 2009.

CAMPBell, A., CONVERSE, P. E. MILLER, W. E, STOKES, D. The American Voter. New York: John Wiley, 1960.

CLARK, T. N.; HOFFMANN-MARTINOT, V. The new political culture. Boulder: Westview Press, 1998.

CROZIER, M, HUNTINGTON, S.; WATANUKI, J. The crisis of democracy: Report on the governability of democracies to the Trilateral Commission UP. New York: 1975.

DAHL, R. A. On political equality. Yale University Press, 2006.

DALTON, R.; KLINGEMANN, H. H. Oxford handbook of political behavior. Oxford: Oxford University Press, 2007.

DALTON, R. The good citizen: how a younger generation is reshaping american politics. Washington, DC: Congressional Quarterly, 2009.

DALTON, R.; ROHRSCHNEIDER, R. "Political action and the political context: a multi-level model of environmental activism". In: Fuchs, D.; Roller, E.; Wessels, B. (Eds.). Citizen and democracy in east and west: studies in political culture and political process. Wiesbaden: Westdeutscher Verlag, 2002.

DALTON, R. J. Citizen politics: Public opinion and participation in advanced industrialdemocracies. 3rd edition. New York: Seven Bridges Press, 2002.

DALTON, R; SICKLE, V.A.; WELDON, S. "The individual-institutional nexus of protest". Brithish Journal of Political Science, n. 40, 2009, p. 51-73.

DELLA-PORTA, D. Introdução a Ciência Política. Lisboa: Editorial Estampa, 2003.

. "Paths to february 15 protest: social or political determinants? To be published". In: Dieter Rucht and Stefaan Walgrave (eds), Protest Politics antiwar mobilization in western democracies, 2008. Disponível em www.Ise.ac.uk/ Depts/global/PDFs/Peaceconference/dellaporta.doc. Acesso em dezembro de 2008. 
FILLIEULE, O. "Introdution et propositions pour une analyse processuele de l'engagement individual". In: Fillieule, O. \& Mayer, N. Devenir militants. Revue Française de Science Politique, 51 (1), 2001, p. 19-25.

GOODIN, R. E.; KLINGEMANN, H. D. (eds.), A new handbook of political science, Oxford: Oxford University Press, 1996

HAFNER-FINK, M. Using cluster analysis to discover political participation typologies in a comparative context. Paper prepared to CINEFOGO WP 11 WORKSHOP: "Methodological Challenges in Cross-National Participation Research", 2009. The Hague, 16-19 january, 2009. Disponível em em http://cinefogo.cuni.cz/index.php?\&I=0\&w=16\&id_event=92. Acesso em novembro de 2010.

HIRSCHMAN, A. O. Exit, voice, and loyalty-responses to decline in firms organizations, and states. Harvard University Press: Cambridge, 1970.

HUNTINGTON, S.; NELSON, J. M. No easy choice: political participation in developing countries. Cambridge, Harvard University Press, 1977.

HUSTIN, L.; DENK, T. The black box problem in the study of political participation. Paper prepared to CINEFOGO WP 11 WORKSHOP: "Methodological Challenges in Cross-National Participation Research". The Hague, 16-19 january, 2009. Disponível em em http://cinefogo.cuni.cz/index.php?\&l=0\&w=16\&id_event=92. Acesso em novembro de 2010.

INGLEHART, R.; CATTERBERG, G. "Trends in political action: the development trend the post-honeymoon decline". In: International Journal of Comparative Sociology IJCS, Vol. 43 (3-5), 2002, p. 300-316.

INGLEHART, R.; WELZEL, C. Modernização, mudança cultural e democracia: a sequência do desenvolvimento humano. São Paulo: Francis, 2009.

JENNINGS, M. K. et al. "Continuits in political action: a longitudinal study of political orientations in three western democracies". Walter de Gruyter. Berlin, New York, 1990.

JOHNSON, J. "Problemas conceituais como obstáculos ao progresso em Ciência Política". In: Teoria e Sociedade, v. 12, n. 1, 2004.

KALAYCIOGLU, E.; TURAN, I. "Measuring political participation : a cross-cultural application". In: Comparative Political Studies, vol. 14, 1981, p. 123-135.

KATZNELSON, I. ; MILNER, I. V. (Eds.). Political science: the state of the discipline. New York: W. W. Norton, 2002, p. 433-461. 
LAZARSFELD, P. F., BERELSON, B.; GAUDET, H. The People's Choice: How the Voter Makes Up His Mind in a Presidential Campaign. New York: Columbia University Press, 2nd Edition, 1948.

LEIGHLEY, J. E. "Attitudes, opportunities and incentives: a field essay on political participation". Political Research Quarterly, 48, 1995, p. 181-209.

LIJPHART, A. "Unequal participation: democracy's unresolved dilemma". The American Political Science Review, V. 91, No. 1 (Mar.), 1997, p. 1-14.

LIPSET, S. (Ed.). The encyclopedia of democracy. 4 vols. Londres, 1995.

MARSH, A. Explorations in unorthodox political behaviour: a scale to measure "protest potential". European Journal of Political Research, 2, 1974, p. 107-129.

MILBRATH, L. W. Political Participation. Chicago: RandMcNally, 1965.

MILBRATH, L.; GOEL, M. L. Political participation. Boston: University Press of America, 1977.

NEWTON, K.; GIEBLER, H. "Patterns of participation: political and social participation in 22 Nations". Discussion Paper, Berlin, july, 2008.

NEWTON, K.; MONTERO, J. R.: "Patterns of political and social participation in Europe". In: Jowell, R. et al. (Eds.): Measuring attitudes cross-nationally - Lessons from the European Social Survey. Sage: London, 2007.

NORRIS, P. Democratic Phoenix: reinventing political activism. Cambridge: Cambridge University Press, 2002.

NORRIS, P. "Political activism: new challenges, new opportunities". In: BOIX \& STOKES, D. The oxford handbook of comparative politics. Oxford: Oxford University Press, 2007, p. 628-652. Disponível em http://ksghome.harvard. edu/ pnorris/Acrobat/Boix\&stokes-chap26.pdf. Acesso em fevereiro de 2009.

PASQUino, G. Curso de Ciência Política. 2 ed. Lisboa: Princípia, 2010.

PIZZORNO, A. “Condizioni della participazione política”. In: Pizzorno, A. Le radici della politica assoluta. Milano, Feltrinell, 1966.

. "Colloquio con Alessandro Pizzorno". Revista Parttecipazione e Conflito. Vol. 1, n. 1, 2007, p. 175-188.

PRZEWORSKI, A.; TEUNE, H. The logic of comparative social inquiry. New York, Wiley, 1970. 
PUTNAM, R. Comunidade e democracia: a experiência da Itália moderna. Rio de Janeiro: Ed. FGV, 1996.

Solo en la bolera. Colapso y resurgimiento de la comunidade norteamericana. Barcelona: Galaxia Gutenberg, 2002. . El declive del capital social. Barcelona: Galaxia Gutenberg, 2003.

RIBEIRO, E.; BORBA, J. "Participação e pós-materialismo na América Latina”. In: Revista Opinião Pública. Campinas, Vol. 16, no 1, junho, 2010a, p. 28-63.

. "Os determinantes da participação no Orçamento Participativo: uma comparação entre Porto Alegre e Montevidéu". Encontro anual da ANPOCS, GT Comportamento Político, 2010b.

ROBINSON, J. P. et. al. (eds.), Measures of political attitudes. San Diego, CA: Academic Press, 1999.

SABUCEDO J. M.; ARCE, C. "Types of political participation: a multidimensional analysis". In: European Journal of Political Research, Vol. 20, Number 1, 1991, p. 93-102.

STOLLE, D.; HOOGHE, M.; MICHELETTI, M. "Politics in the Supermarket: political consumerism as a form of political participation". International Political Science Review, 26 (3), 2005, p. 245-269.

TARROW, S. Poder em movimento: movimentos sociais e confronto político. Petrópolis: Vozes, 2009.

TEORELL, J., TORCAL, M.; MONTERO, J. R. "Political participation: Mapping the terrain". In: Van Deth, Montero, J. R. \& Westholm, A (eds.), Citizenship andinvolvement in european democracies: a comparative analysis. London: Routledge, 2007, p. 334-357.

TEORELL, J. "Political Participation and three theories of democracy: a research inventory and agenda". European Journal of Political Research, 45(5), 2006, p. 787-810.

TILLY, C.; TARROW, S. Contentious politics. Boulder: Paradigm Publishers, 2007. TOPF, R. "Beyond electoral participation". In: Klingemann, H. D. \& Fuchs, D. (Eds.). Citizens and the State. New York: Oxford University Press, 1995a, p. 53-91. . "Electoral participation". In: Klingemann, H. D. \& Fuchs, D (Eds.), Citizens and the State. New York: Oxford University Press, 1995b, p. 27-51. 
VAN DETH, J. W. "A note on measuring political participation". Quality and Quantity, 120, 1986, p. 261-272.

. "Studying political participation: towards a theory of everything?" Paper presented at the ECPR Joint Sessions of Workshops, Grenoble, April 6-11th, 2001.

. "Establishing equivalence". In: Landman, T. \& Robinson, N. The sage handbook of comparative politics. London: Sage, 2009.

VAN SCHUUR, W. H. "Mokken Scale Analysis: Between the guttman scale and parametric item response theory". In: Political Analysis 11, 2003, p. 139-163.

VERBA, S.; NIE, N. H. Participation in America-Political Democracy and Social Equality. Harper \& Row Publishers: New York, 1972.

VERBA, S.; NIE, N. H.; KIM, J. O. The modes of democratic participation: a crossnational comparison. Sage: Beverly Hills, California, 1971.

. Participation and political equality - a seven-nation comparison.

The University of Chicago Press: Chicago, 1978.

VERBA, S., SCHLOZMAN, K.L.; BRADY, H.E. Voice and equality. Civic voluntarism in American politics. Cambridge, Mass.: Harvard University Press, 1995.

. "Beyond SES: a resource model of political participation". In: The American Political Science Review, Vol. 89, No. 2 (Jun., 1995), p. 271-294.

VERBA, S. "Fairness, equality, and democracy: three big words". In: Social Research: an international quarterly of Social Sciences, 73(2), 2006, p. 499-540.

WELZEL, C.; INGLEHART, R., DEUTSCH, F. S. "Social capital, voluntary associations and collective action: Which aspects of social capital have the greatest 'Civic'Payoff?" In: Journal of Civil Society, Vol. 1, No. 2, Sept, 2005, p. 121-146.

WHITELEY, P. F. "Racional choice and political participation - evaluating the debate". In: Political Research Quarterly, 48, 1995, p. 211-233. 